\title{
Design and Investigation of Energy Harvesting System from Noise
}

\author{
Junayed Hossain, Nazmus Sadad Ovi, Mohammad Monirujjaman Khan* \\ Department of Electrical and Computer Engineering, North South University, Dhaka, Bangladesh \\ Email: *monirujjaman.khan@northsouth.edu
}

How to cite this paper: Hossain, J., Ovi, N.S. and Khan, M.M. (2021) Design and Investigation of Energy Harvesting System from Noise. Energy and Power Engineering, 13, 307-321.

https://doi.org/10.4236/epe.2021.138021

Received: June 21, 2021

Accepted: August 3, 2021

Published: August 6, 2021

Copyright ( 2021 by author(s) and Scientific Research Publishing Inc. This work is licensed under the Creative Commons Attribution International License (CC BY 4.0).

http://creativecommons.org/licenses/by/4.0/

(c) (i) Open Access

\begin{abstract}
In order to survive in this modern world, electricity is an essential thing. Electricity allows us to power the technology we use every day. Without electricity, people can't imagine their lives. As a developing country, Bangladesh still lacks electricity every day. The electricity supply to the rural areas is very poor. It is known that energy can be converted from one form to another form. As noise is the energy, it can also be converted into various forms of energy. Noise can be represented as a sound that is loud or unpleasant and causes disturbances such as street traffic sounds, construction sounds, airports, etc. Using a suitable transducer, noise (sound) energy can be transferred into a viable source of electricity generation. This can be accomplished by employing a transducer and converting noise-induced vibrations into electrical energy. Our main goal is getting enough energy, reducing the pressure of the main grid of electricity and decreasing fossil fuel imports. This paper presents the design and investigation of an energy harvesting system from noise. In this paper, an application is designed to get energy from noise by using a speaker as a transducer. Voltage has been stepped up by using a transformer, a diode which gives DC value which can be tapped into a battery and provide energy from the battery when it is needed. The embedded device was initially tested by clapping hands and tested further by using car horns. The vibrations created by car horns and other noises have been converted into electrical energy through the principle of electromagnetic induction. In total, the application produced optimal results of $0.5-1.0$ volts which were stepped up using a transformer while maintaining the whole system being low cost and user-friendly.
\end{abstract}

\section{Keywords}

Electromagnetic Induction, Electromotive Force, Sound Energy, Transducers, Energy Harvest 


\section{Introduction}

Noise is a loud and unpleasant sound that causes disruptions, such as street traffic, construction noise, and so on [1]. It is a different type of energy. Sound, on the other hand, does not spread without a medium. Noise or sound which has waves can travel $333 \mathrm{~m} / \mathrm{s}$ in the air [2] and faster through liquids and solids [3]. When an object is hit, the air particles next to the particle's skin vibrate and collide with other particles, and this vibration is then transmitted through the air or any other medium. Decibels are the units used to measure the volume of sound [4]. A normal person can hear or detect sounds that range between 0 decibel to about 150 decibels where sounds between 120 decibels to 150 decibels create pain [5]. High decibel sound or noise generates energy which is called sound energy. There are several ways that can be used for the conversion of sound energy to electrical energy. It can be done by trapping the sound and converting it into electrical power by using a proper transducer.

As we are a huge population, we have a large demand for electricity. Windmills, solar panels, and other renewable energy sources have recently become popular. But sometimes the flow of wind stops and people do not get any energy from solar panels at night. That's why electricity is not being generated as expected. Still, because of the lack of electricity, many people in the rural areas of Bangladesh do not have access to proper education, healthcare etc. In 2018, approximately 85.2 percent of the overall population of Bangladesh had access to electricity where 78.3 percent of residents in our country's rural areas of Bangladesh had access to power [6].

For the past several years, the world has been trying to invest and work in renewable energy, which has led scientists to think about transforming electrical energy from noise.

There are many elements that have numerous kinds of shapes. For example, rectangular or circular shaped plates can be used as piezoelectric materials. These materials convert sound to mechanical energy and mechanical energy converts it into electrical energy [7]. In an experiment, the electric energy created in the piezoelectric element was measured utilizing the acoustic excitation of the speaker connected to the resonator. The speaker was tuned to produce only 100 decibels of white noise. In the measurement, the mean value of the voltage generated over a 10 -second period was used. The voltage measurement results for the piezoelectric device's rectangular plate confirmed the generation of voltages ranging from 0.22 to 0.70 volts [7].

Rahman et al., in [8] present us information that a system has been updated and the system can convert vibration and sound into electrical energy. The produced energy is measured in volts in this project by doing experimentation. The maximum voltage of the experiment measured was 2.96 volts. This report presents the results of a vibration experiment performed in the lab on a diesel engine [8]. It can be said that different devices vibrate at varying levels and they can release different amounts of energy. Another graph confirms that various 
types of piezoelectric material can produce energy at different sound levels [9]. One of the piezoelectric materials (QB220-503YB) generated power at a measurement of $2057.2(\mu \mathrm{W})$ at 96 decibels with a voltage of $3.894\left(\mathrm{~V}_{\mathrm{rms}}\right)$. The graph shows that more power can be obtained at high decibel [9].

Charan et al. [10] discussed various methods, including the acoustic metamaterial sound energy harvesting method, the use of capacitor-like plates, and the electromagnetic method. By following the electromagnetic induction method, electromotive force (emf) is produced across a conductor by a fluctuating magnetic field [11]. The obtained voltage from the car horn was 1.62 volts at 90 decibel (db) and 2.70 volts at 114 decibels (db) from motorbike silencer [11]. It is known that, nowadays in most parts of the world, people are making an effort to become more environmentally friendly by choosing to use renewable energy [12] [13] [14]. For the purpose of implementing renewable energy in [13], the total quantity of energy generated by the highway with both traffic-induced turbulence and highway inherent natural wind was estimated by the authors. By the estimation, generated peak power was 43.1 watt (W) from the sedan, 54.4 watt (W) from SUV and VAN, 513.3 watt (W) from the truck [13]. This demonstrates that the energy captured along the route is sufficient for modest applications such as street lighting systems.

A sound energy-based hybrid method for charging mobile phone batteries has been shown in a paper. Sound waves are also called mechanical waves. This wave consists of compressions and rarefactions. The mechanical form of energy has been converted into electrical energy by using nanogenerators. Basically, three types of nanogenerators are used to convert into electrical energy and they are: piezoelectric nanogenerator, triboelectric nanogenerator and pyroelectric nanogenerator [15].

The above systems all use different types of transducers. There are many kinds of piezoelectric materials which provide several amounts of outputs depending on the quality of the product. Besides, piezoelectric material is very expensive and, comparatively, does not last longer. The electromagnetic method seemed good, but the circuit is very hard and complex. If something goes wrong with the existing circuit, then it is very difficult to resolve. Besides, other renewable energy sources can not provide energy all day long.

This paper discusses design and provides a complete and simple solution to the energy harvesting method from noise in Section 1. A simple speaker was used as a transducer to generate emf in the presence of sound and vibration. This speaker can be installed anywhere to tap sound. Furthermore, a transformer will help to step up the obtained voltage or energy from the speaker. A diode is installed to convert AC voltage to DC voltage. The energy will be stored in a battery which will provide the energy when it is needed. LDR will sense the sunlight, which means road lights will be on at night automatically and LDR will be controlled by a microcontroller named Arduino uno. A code has been implemented for LDR and discussed about all equipment in Section 2. The re- 
mainder of this paper focuses on the project's outcome, with several data from the experiment provided and discussed in Section 3, and Section 4 containing the paper's conclusion.

\section{Method and Methodology}

This section goes into the procedures and materials that are employed to achieve the goal. The single most important goal of this project is to generate electrical energy from sound energy. The first subsection presents a simple structure of the system, followed by a discussion of the object's design; hardware implementation of the system including the cost breakdown; finally, the system's operational methodology will indeed be developed.

\subsection{Outline of Full System}

The full system is depicted in Figure 1 as a block diagram. The system consists of one sound transducer. Sound transducers are used for converting sound energy into electrical energy. The voltage produced by these sound transducers is very small in amount. This generates a small amount of voltage AC. Then, to get maximum voltage here, a step-up transformer is connected. A step-up transformer has two sides. One is primary and the other one is secondary. In this case, the winding of the secondary side is greater than the primary side as it is a step-up transformer. Following that, a diode is added to produce only the positive half cycle, which is now DC and aids in the storage of the maximum voltage in a battery. The battery provides energy through the Arduino. The Arduino decides whether the output is required or not. Figure 1 depicts the process by which the system achieves its goal. If this technique is followed repeatedly, the device will generate electricity from sound or noise.

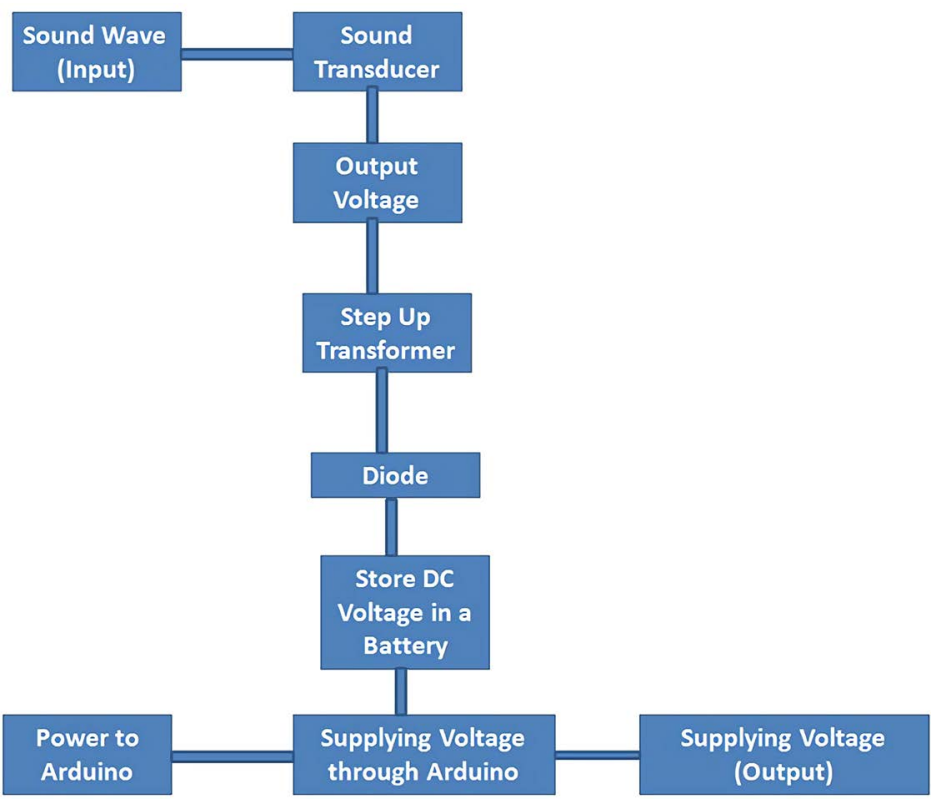

Figure 1. A full systm block diagram. 


\subsection{Object Detection}

To convert sound energy into electrical energy, a single speaker has been used. This speaker will operate as a sound transducer for the system. We know that sound energy is a type of mechanical energy that forms waves as it passes through the air. In this system, when sound or noise passes through the diaphragm, then the thin diaphragm starts to vibrate. The diaphragm is the frontal part of the speaker and the inside of the speaker has three coils, two of which are fixed coils and the other one is flexible. The coil attached to the diaphragm starts moving along with it. The coil's movement generates a magnetic field surrounding it. The magnetic field produces a current in the coil, as per Faraday's law. The law states that a magnetic field generates electromotive force (emf) throughout a conductor. By applying this technique, we can simply produce electrical energy from noise or sound. This section goes into greater detail on the system's process. Figure 2 depicts a block diagram which is the transducer algorithm used for our design.

Figure 2 illustrates the main technique of converting sound energy into electrical energy. It can be done by any speaker or made-up device by following the technique. Good quality speakers and high-level sounds are preferable for a better output.

The decibel scale is used to measure the power of sound. A normal person can hear or notice noises ranging from 0 decibel (threshold of human hearing) to about 150 decibels where sounds between 120 decibels to 150 decibels create pain. We know that high decibel sound or noise generates waves in the air, which is also a form of energy.

\subsection{Design of Interface}

The important benefit of our approach versus earlier attempts is its ease of usage. We utilized the $\mathrm{C}++$ library to develop a simple, functional interface that

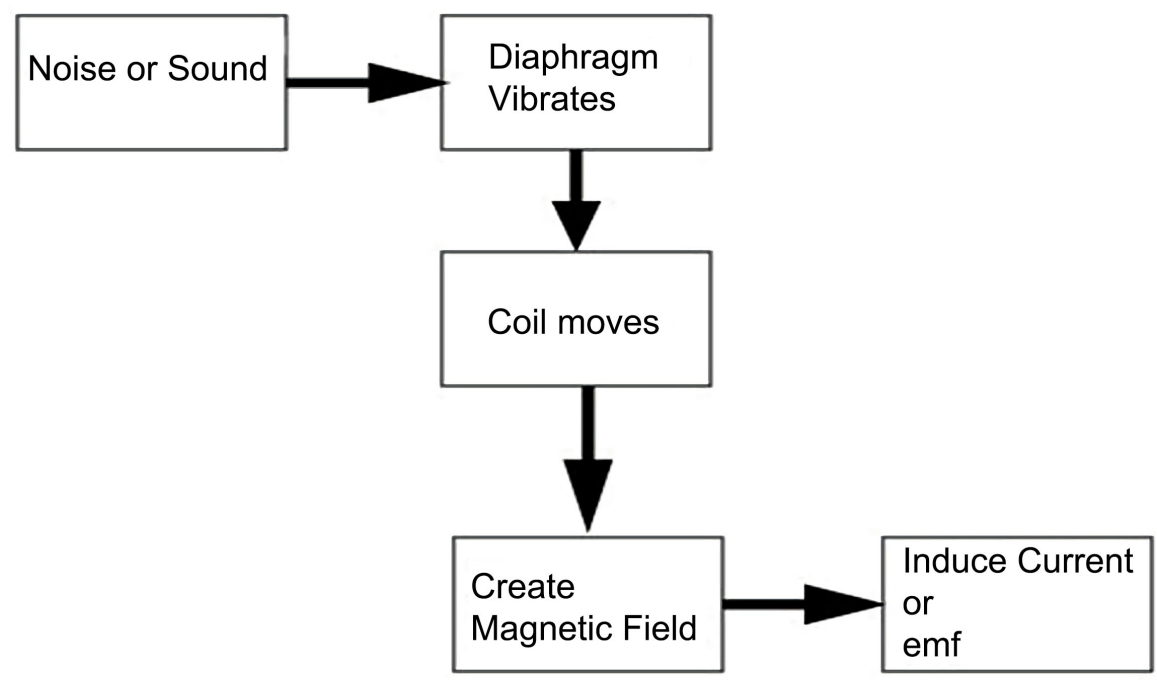

Figure 2. The block diagram of converting sound energy into electrical energy of a transducer. 
helps to feed the stored voltage to the load and provides a lot of information about how the system works.

The interface design discussed in this section is implemented as a system output. In the following subsection, we will go over the system's hardware design. It includes the electronic components which are used for the system as well as a sound transducer to produce electrical energy, a step-up transformer to get maximum voltage and a diode to store energy in a battery and, lastly, an Arduino for supplying the output.

\subsection{Hardware Design}

The circuit diagram in Figure 3 illustrates the hardware design. The circuit diagram starts with a speaker, a sound transducer, a step-up transformer, diode, battery, Arduino, LDR (Light Dependent Resistor) and LED (Light Emitting Diode). All these components are connected with each other through wires. The microcontroller, which is also known as Arduino, is connected with a battery (output) and LDR with wires. The LDR gives a signal to the Arduino to supply output as stored voltage to the LED. The components of this project are listed and briefly described in Table 1. Figure 3 depicts the completed, simple circuit diagram. The designed circuit has one sound transducer, one step up transformer, one diode, one battery, an Arduino Uno microcontroller, one LDR and some LED. The transducer helps to take a sound wave as an input and convert it into electrical energy, which is then passed through a step-up transformer to achieve maximum voltage. A diode is connected to a transformer to convert AC voltage to DC voltage which will be stored in the battery. The Arduino will supply the stored voltage to an LED that will be connected in parallel, with the negative terminals of the LED connected to the ground and the positive terminals of the LED connected to the Arduino's pin number 7, and the LDR will then

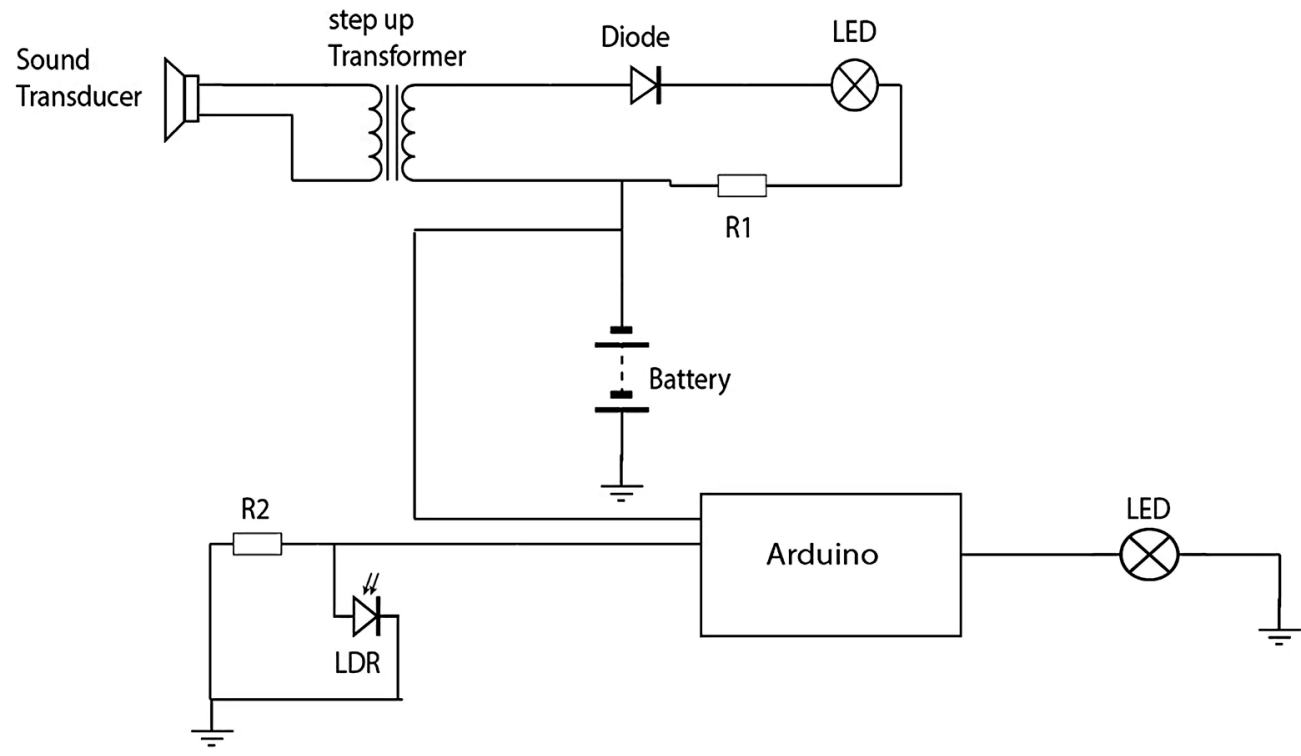

Figure 3. The block diagram of converting sound energy into electrical energy of a transducer. 
Table 1. Description of components.

\begin{tabular}{cl}
\hline Components & \multicolumn{1}{c}{ Description } \\
\hline Arduino & $\begin{array}{l}\text { A microchip also known as microcontroller. As we need the data of inputs } \\
\text { and outputs, in this paper it is used by Arduino to control the system. }\end{array}$ \\
Sound Transducer & $\begin{array}{l}\text { A sound transducer converts sound energy into electrical energy. In this } \\
\text { paper, it is used to convert sound energy into electrical energy. }\end{array}$ \\
Step-up Transformer & $\begin{array}{l}\text { As we increase the input voltage, the secondary coil has more turns than the } \\
\text { primary coil. In this paper, it is used to maximize the obtained voltage. }\end{array}$ \\
Diode & $\begin{array}{l}\text { Diode only conducts when forward biased. We know the diode conducts in } \\
\text { half cycles and insulates during other cycles. This property is used for } \\
\text { rectification of AC into DC. In this paper, a diode is used for storing voltage } \\
\text { into a battery. } \\
\text { A 9V power supply is utilized to help store the generated voltage and to } \\
\text { power the LED via the microcontroller. } \\
\text { A light dependent resistor is called LDR. In this paper, it will work as a } \\
\text { Lires }\end{array}$ \\
sensor at night and to run the Arduino to supply output. \\
It is used to show stored voltage and other readings. \\
Flexible wire having connections on both ends enables the wires to be joined \\
to other pins.
\end{tabular}

give the signal to the Arduino and function as a sensor at night. The circuit is depicted in Figure 3 along with component descriptions. The components are depicted in Table 1, which also displays the component costs.

After producing the voltage of the system, it will be stored in a battery and Arduino works to control the voltage as input and output. The working process of Arduino is shown in Figure 4.

There is an impact on the transformer because maximum voltage can be stored in the battery which uses Arduino. The electrical energy which is produced by a sound transducer is too small to use. For this reason, a step-up transformer is connected with a transducer to get maximum voltage use. The alternating low voltage is converted to alternating high voltage via a step-up transformer and the winding on the secondary side exceeds the winding on the primary side. The working principal of the step-up transformer is shown in Figure 5 , which is used for this proposed design.

In this paper, a diode plays an important role which will be discussed below.

Figure 6 depicts the performance of forward biased diodes in our system. The diode performs in half cycles and insulates in the other cycles. This property is used to convert AC to DC. A diode is used to store voltage in a battery in this example.

An essential component of our system is the battery where the converted electrical energy will be stored. This component will be discussed below Figure 7 .

According to Figure 7, a 9V power source is used to help store the generated voltage and to supply power to the consumer via the microcontroller and the LDR. 


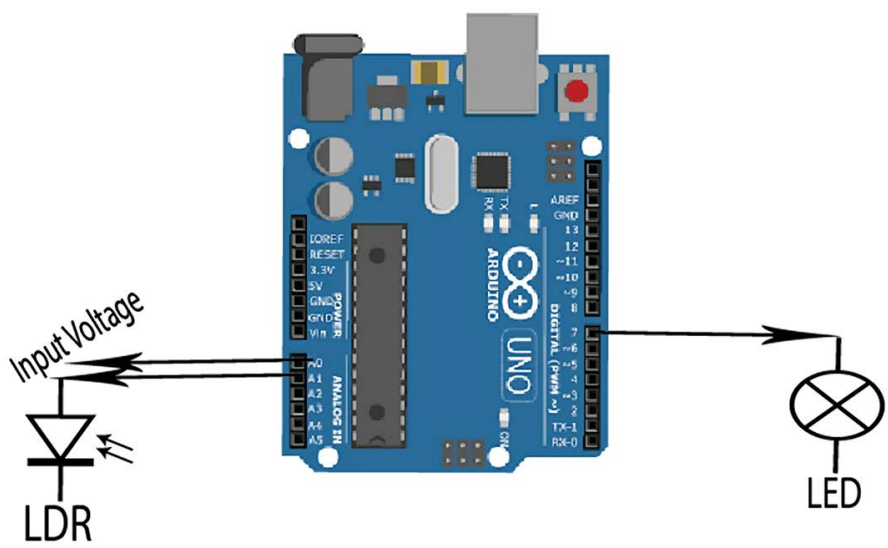

Figure 4. The Arduino of the system which takes input from the battery and signal from LDR to supply the voltage as output to the LED.

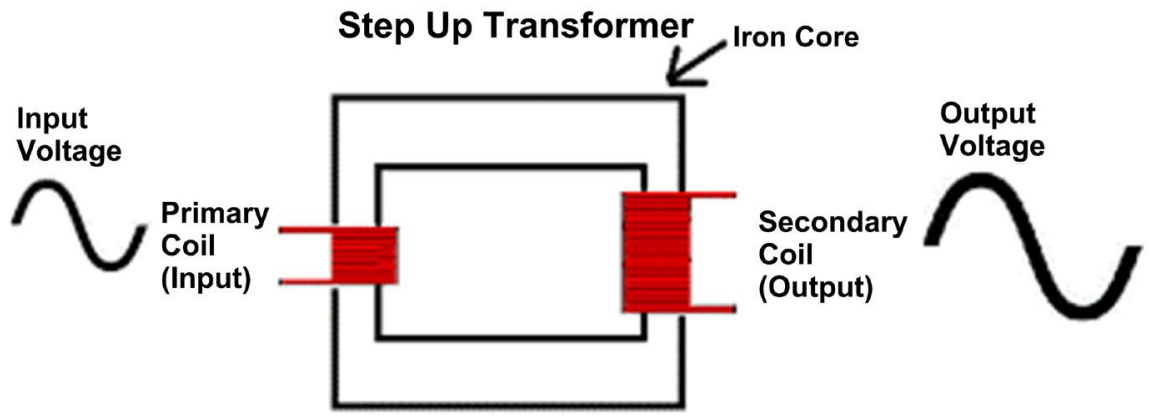

Figure 5. For getting maximum voltage by a step transformer.

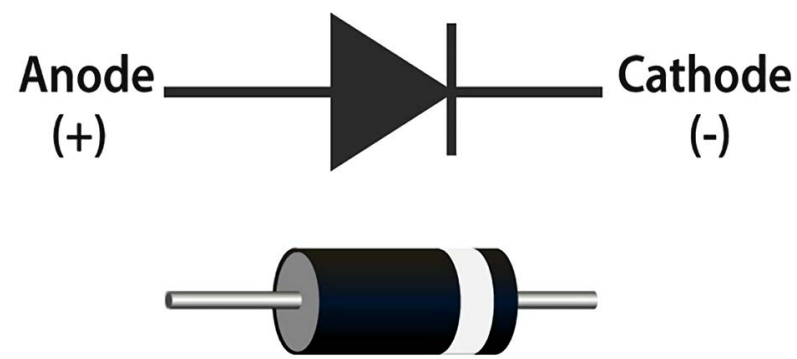

Figure 6. Converting AC to DC energy.
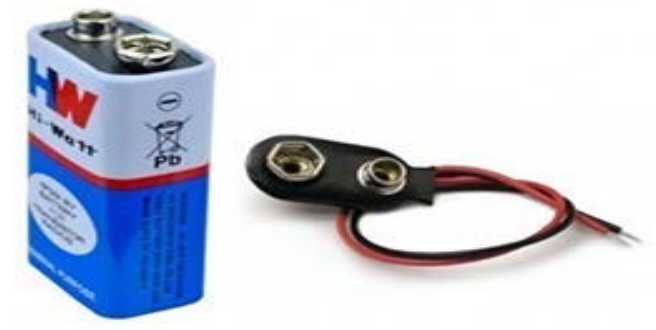

Figure 7. Battery.

To make sure that the energy is getting, LEDs are used, which will be discussed below Figure 8 . 


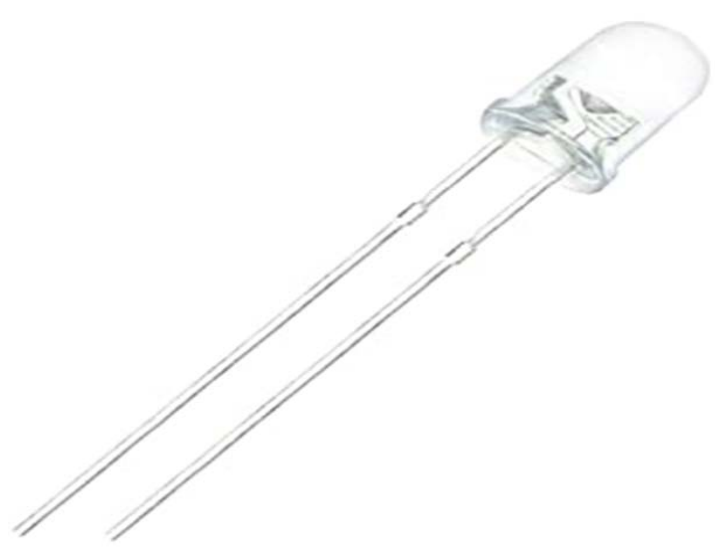

Figure 8. Light emitting diode (LED).

When an electric current is conducted through a light-emitting diode or LED, it emits light. When the particles that carry the current collide, light is created. The obtained electrical energy can be used to power lights, which can eliminate darkness.

Figure 9 depicts the importance of LDR. It aids in the detection of lights.

LDRs are used to detect light levels in devices such as automatic light systems. Their resistance diminishes with increasing light intensity: in the dark and at low light levels and vice versa. In our project, Arduino will take help from LDR to determine whether it is a suitable time to stop or to start the Arduino in order to provide power to the customer. Table 2 lists the quantity, price and required components that were used to develop the proposed system. From the Table 2, it is observed that the device is low cost. The total cost of the required components is only 1972 Bangladeshi Taka, which is equivalent to 23.25 US Dollars.

\section{Result and Analysis}

This section covers the system created for this project and displays the findings obtained by examining the system; investigating the results to put them into context. The entire system is made up of the following components: sound transducer, step up transformer, diode, battery, LED, Arduino, consisting of LDR which works as a sensor. The prototype is shown below in Figure 10.

The proposed system can produce around $2 \mathrm{mV}$ to a maximum of 28 or 30 $\mathrm{mV}$ from city noise.

Figure 10 depicts a model of an energy harvesting system based on noise, as well as the physical connections between the tools.

In our country, the maximum available sound energy comes from car horns and silencers. Figure 11 and Figure 12 show that various types of sound show different $(\mathrm{db})$ readings. The readings were recorded on a smart phone.

Figure 11 sums up that a car horn was made and the maximum value of the sound level is $100 \mathrm{db}$.

Figure 11 depicts a noise produced by an old air cooler, which produces a higher sound level $(\mathrm{db})$ with a maximum value of $114 \mathrm{db}$. 
Table 2. The prices of the hardware components.

\begin{tabular}{cccc}
\hline Component & Quantity & Price/Unit (BDTK) & Price (BDTK) \\
\hline Arduino & 1 & 465 & 465 \\
Sound Transducer & 2 & 250 & 500 \\
Battery & 1 & 40 & 40 \\
Step up transformer & 1 & 700 & 700 \\
Breadboard and wires & - & - & 180 \\
White LED & 10 & 5 & 50 \\
Diodes & 1 & 30 & 30 \\
LDR & 1 & 7 & 7 \\
Total & - & - & $1972 /=$ \\
\hline
\end{tabular}

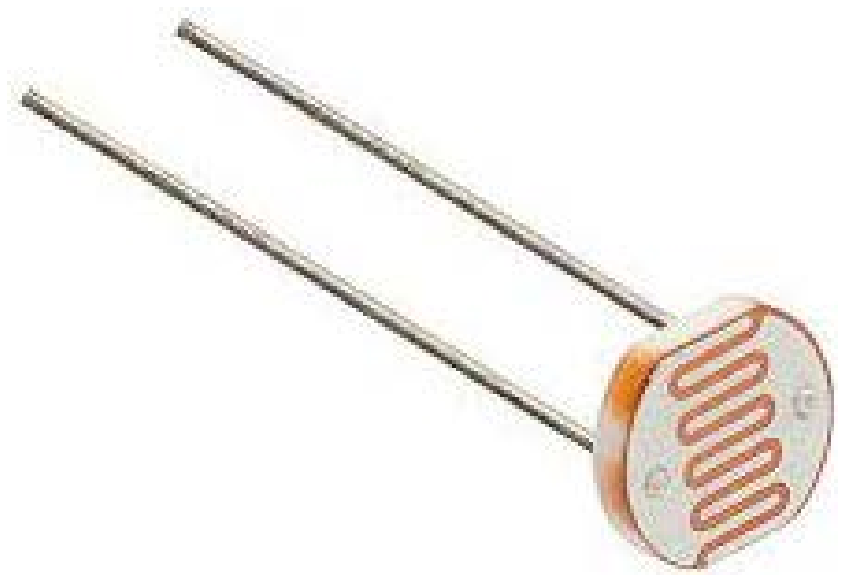

Figure 9. Light dependent resistance (LDR).

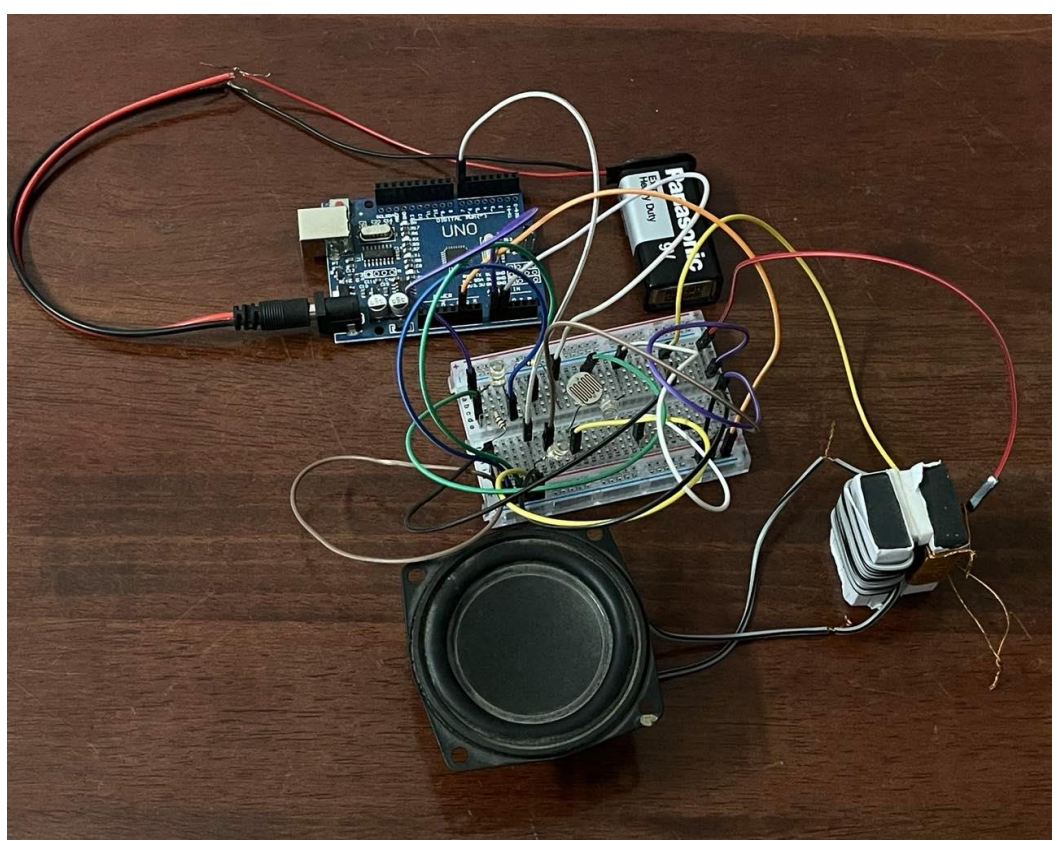

Figure 10. Prototype of energy harvesting system from noise. 


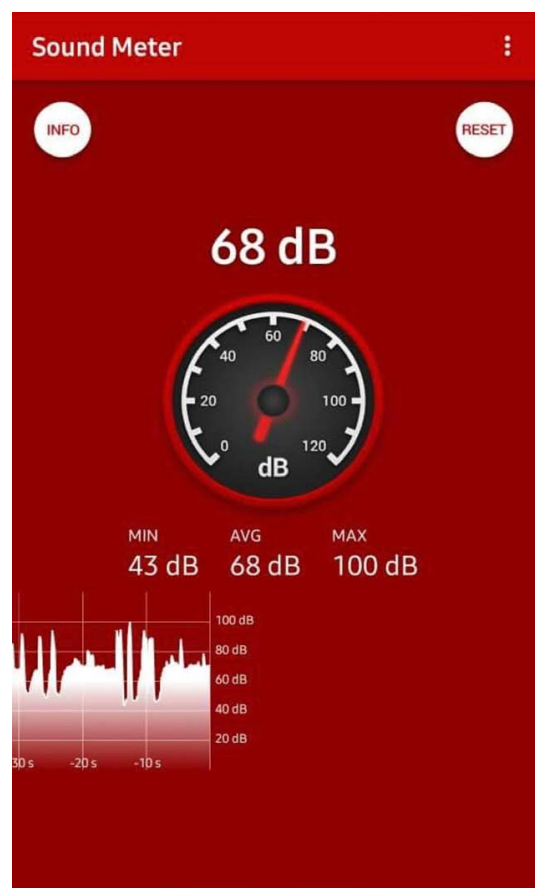

Figure 11. Sound level $(\mathrm{db})$ of a car horn.

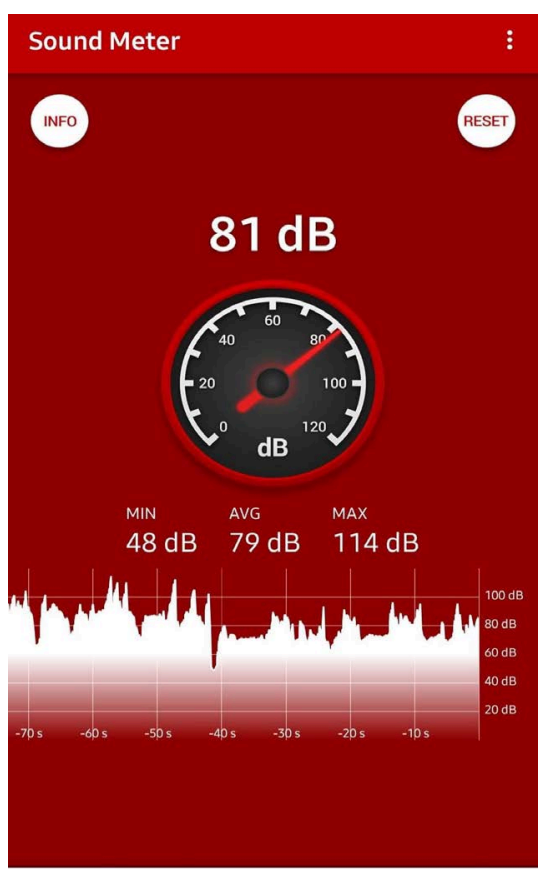

Figure 12. Sound level $(\mathrm{db})$ of an air cooler.

Figure 11 and Figure 12 were obtained through an app on a smart device. This particular app with coordination of the smartphone's microphone detects the level of sound, measures it on a decibel scale and illustrates the readings on the smartphone's screen. This means a high level of sound was created by a car horn and an air cooler machine. One of our project's primary requirements is a high level of sound to turn it into electrical energy. Figure 11 and Figure 12 
prove that we have got a sufficient level of sound which can be converted into electrical energy.

The experiment results are shown below in Table 3 (car horn) and in Table 4 (air cooler). A quality sound wave crosses through the system, then it starts to work. First, it will produce electrical leads which are sinusoidal-voltage (or square-wave) signals. This small voltage transformer maximizes the voltage and, with the help of a diode, the AC voltage is converted into DC and stored in a battery.

This stored voltage is supplied by Arduino. The Arduino is coded for lighting street lights. When the sun sets, the light turns on, and when the sun rises, the light turns off automatically, with the help of an LDR (Light Dependent Resistor). The blink (or continuous) of an LED confirms that the voltage is being supplied through Arduino.

1) When the air cooler is on at a distance of one meter. The result of sound vs voltage is shown in Table 4.

2) In Figure 13, the digital multimeter displays us the voltage reading of the system experimented by the air cooler.

Figure 13 displays a random voltage reading at a random sound level. Because of the high degree of noise, the sound wave strikes the speaker's diaphragm. As soon as the sound wave strikes the diaphragm, it begins to vibrate, releasing energy. We detected a voltage of $27.2 \mathrm{mV}$ with a digital multimeter, with a maximum reading of $28 \mathrm{mV}$.

From this display reading we can understand that the voltage reacts with the level of sound applied.

Table 5 shows a comparison of the minimum and maximum values between

Table 3. Sound level of a car horn (db) vs obtained voltage $(\mathrm{mV})$.

\begin{tabular}{ccc}
\hline SL No. & Sound Level $(\mathrm{db})$ & Voltage $(\mathrm{mV})$ \\
\hline 1. & 94 & 12 \\
2. & 96 & 14.7 \\
3. & 97 & 18 \\
4. & 98 & 18.8 \\
5. & 100 & 22 \\
\hline
\end{tabular}

Table 4. Sound level of air cooler $(\mathrm{db})$ vs obtained voltage $(\mathrm{mV})$.

\begin{tabular}{ccc}
\hline SL No. & Sound Level $(\mathrm{db})$ & Voltage $(\mathrm{mV})$ \\
\hline 1. & 75 & 2 \\
2. & 80 & 2.5 \\
3. & 90 & 10.5 \\
4. & 100 & 20 \\
5. & 114 & 28 \\
\hline
\end{tabular}


Table 5. The outcomes of others vs our outcomes.

\begin{tabular}{lccclc}
\hline & \multicolumn{2}{c}{ Other People's results } & \multicolumn{2}{c}{ Our System's Results } \\
\hline Min value & $1.62 \mathrm{~V}(90 \mathrm{db})$ & $0.22 \mathrm{~V}$ & $1.58 \mathrm{~V}$ & Min value & $2 \mathrm{mV}(75 \mathrm{db})$ \\
Max value & $2.70 \mathrm{~V}(114 \mathrm{db})$ & $0.70 \mathrm{~V}$ & $2.96 \mathrm{~V}$ & Max value & $28 \mathrm{mV}(114 \mathrm{db})$ \\
\hline
\end{tabular}

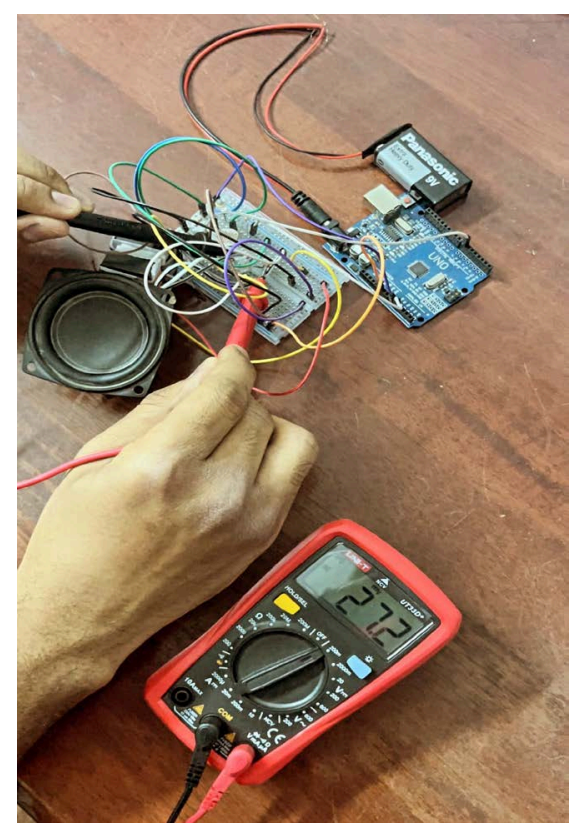

Figure 13. Output voltage at a random noise.

the outcomes of the proposed system and those of others. In comparison to others, our results are quite low. This can be avoided by using a good-quality transformer and sound transducer.

The results that we received were experimented for a period of less than a half minute. To deliver electricity to the bulbs or LEDs, the battery must be charged for an extended length of time. Therefore, we can say that the battery can provide a sufficient amount of energy if the battery gets enough time to be charged.

The system will help us in many ways. It will increase local employment. Where street light does not reach the road, accidents caused by darkness will be removed. This method is so simple that it can be set anywhere.

\section{Conclusion}

This paper investigates sound, presents a design and implements an energy harvesting system from noise. This system consists of a speaker, step up transformer, diode, LED, LDR, resistor, Arduino uno and a battery. This system collects sound by using a speaker, steps up the voltage by a transformer, converts AC to DC by using a diode and finally stores the energy in a battery and Arduino will provide output with the help of LDR when it is required. Furthermore, we put the proposed system unit through its paces with the sounds of an air cooler and a car horn. By testing the system, it is found out that the voltage is directly pro- 
portional to sound level $(\mathrm{db})$. The proposed system in this research study produces a maximum output of about $15 \mathrm{mV}$ at $114 \mathrm{db}$. Overall, this is a technology that is more cost effective than any other electrical energy sources. It has more advantages for the environment than other renewable and nonrenewable sources. The risk of using this method is fairly lower than existing methods while creating a new industry and job opportunities for society. Upcoming initiatives could include a uniquely designed speaker made of a thin layer of diaphragm that moves smoothly and quickly. In this situation, a customized step-up transformer would be a huge success. It would be highly appreciable if our government and society support us in this system to make this technology widely available throughout the country in areas with high sound pollution. In the future, this system can be made more efficient and user-friendly. The proposed system design can be optimized to get more energy from sound. Energy harvesting can also be tried from different sources like thermo electric generators (TEG).

\section{Acknowledgements}

The authors would like to express their gratitude to the Department of Electrical and Computer Engineering of North South University.

\section{Conflicts of Interest}

There are no competing interests among the writers.

\section{References}

[1] Tsao, Y., Su, B., Lee, C. and Wu, C. (2017) An Implementation of a Distributed Sound Sensing System to Visualize the Noise Pollution. International Conference on Applied System Innovation (ICASI), Sapporo, Japan, 13-17 May 2017, 625-628. https://doi.org/10.1109/ICASI.2017.7988503

[2] Lutfiyah, A., Adam, A.S., Suprapto, N. and Putri, N.P. (2018) Correction Factors in Determining Speed of Sound among Freshmen in Undergraduate Physics Laboratory. Journal of Physics Conference Series, 997, Article No. 012024. https://doi.org/10.1088/1742-6596/997/1/012024

[3] Ward, R.J., (2015) Measuring the Speed of Sound in Water. Physics Education, 50, 727-732. https://doi.org/10.1088/0031-9120/50/6/727

[4] Ueda, M., Tanaka, T., Nakamura, K. and Miura, T. (2019) What Is This Sound in $\mathrm{dB}$ ? Pilot Study on Measuring the Degrees of Understanding of Sound Level in University Students. 2019 IEEE International Conference on Engineering, Technology and Education (TALE), Yogyakarta, Indonesia, 10-13 December 2019, 1-4. https://doi.org/10.1109/TALE48000.2019.9225874

[5] Chepesiuk, R. (2005) Decibel Hell: The Effects of Living in a Noisy World. Environ Health Perspect, 113, A34-A41. https://doi.org/10.1289/ehp.113-a34

[6] World Bank (2018) Access to Electricity (\% of Population). The World Bank.

[7] Noh, H. (2018) Acoustic Energy Harvesting Using Piezoelectric Generator for Railway Environmental Noise. Advances in Mechanical Engineering, 10, 1-9. https://doi.org/10.1177/1687814018785058

[8] Rahman, A. and Hoque, M. (2013) Harvesting Energy from Sound and Vibration. 
International Conference on Mechanical. Industrial and Materials Engineering 2013 (ICMIME2013).

[9] Farghaly, Y., Hemeida, F.A. and Salah, S. (2019) Noise Utilization as an Approach for Reducing Energy Consumption in Street Lighting. PLoS ONE, 14, e0219373. https://doi.org/10.1371/journal.pone.0219373

[10] Charan, D.C.S. and Rajpathak, B. (2019) Sound Energy Harvesting Methods. International Journal of Recent Technology and Engineering, 8, 316-320.

[11] Garg, M., Gera, D., Bansal, A. and Kumar, A. (2015) Generation of Electrical Energy from Sound Energy. International Conference on Signal Processing and Communication (ICSC), Noida, India, 16-18 March 2015, 410-412.

https://doi.org/10.1109/ICSPCom.2015.7150687

[12] Irmak, E., Ayaz, M.S., Gok, S.G. and Sahin, A.B. (2014) A Survey on Public Awareness towards Renewable Energy in Turkey. 3rd International Conference on Renewable Energy Research and Applications, Milwaukee, WI, USA, 19-22 October 2014, 932-937. https://doi.org/10.1109/ICRERA.2014.7016523

[13] Han, F., Bandarkar, A.W. and Sozer, Y. (2019) Energy Harvesting from Moving Vehicles on Highways. IEEE Energy Conversion Congress and Exposition (ECCE), Baltimore, MD, USA, 29 September-3 October 2019, 974-978.

https://doi.org/10.1109/ECCE.2019.8912688

[14] Lamnadi, M., Trihi, M. and Boulezhar, A. (2017) Study of a Hybrid Renewable Energy System for a Rural School in Tagzirt, Morocco. International Renewable and Sustainable Energy Conference (IRSEC). Marrakech, Morocco, 14-17 November 2016, 381-386. https://doi.org/10.1109/IRSEC.2016.7984079

[15] Srivastava, V. and Priya, B.R. (2016) A hybrid Approach to Charge Mobile Phone Battery by Sound Energy. International Conference on Advances in Electrical, Electronics, Information. Chennai, India, 27-28 February 2016, 126-129.

https://doi.org/10.1109/AEEICB.2016.7538257 